\title{
A preferência visual percebida em cenas de escritórios
}

\author{
Perceived visual preference in office scenes
}

DEIVSON CAVALCANTE GOMES DE OLIVEIRA

Mestrando em Ergonomia, UFPE (PPErgo), deivsoncgo@hotmail.com

ILAINE MARIA DA CONCEIÇÃO DOS SANTOS

Mestranda em Ergonomia, UFPE (PPErgo), ilainemaria27@gmail.com

LOURIVAL COSTA FILHO

Dr. em Desenvolvimento Urbano, UFPE (NDC | PPGDesign | PPErgo), lourivalcosta@yahoo.com

LAURA BEZERRA MARTINS

Dra. em Arquitetura, UFPE (Ddesign | PPGDesign | PPErgo), bmartins.laura@gmail.com

\section{RESUMO}

A configuração das características ambientais pode influenciar o comportamento humano e o interesse de estar e permanecer no ambiente. Partindo dessa afirmação, este artigo objetiva prover informações empíricas sobre os efeitos da coerência e da complexidade de cenas de escritórios na preferência visual de seus usuários. A investigação empírica foi estruturada a partir de uma Sentença Estruturadora Geral, instrumento básico da Teoria das Facetas, útil no delineamento de pesquisas e no aprimoramento da ferramenta de coleta dos dados que, nesta pesquisa, contou com um questionário online para abordar 23 técnicos administrativos, e com uma tabela de distribuição das frequências para interpretar os resultados. As evidências empíricas mostraram que a coerência média/alta e a complexidade mínima favorecem estar e/ou permanecer em cenas de escritórios; já a coerência baixa e a complexidade máxima representam o oposto.

PALAVRAS-CHAVE: cenas de escritórios, preferência visual, ergonomia do ambiente construído.

\section{ABSTRACT}

The configuration of environmental characteristics can influence human behavior and the interest in being and staying in the environment. Based on this statement, this article aims to provide empirical information on the effects of coherence and the complexity of office scenes on visual preference of their users. The empirical investigation was structured based on a General Mapping Sentence, a basic instrument of Facet Theory, useful in designing research and improving the data collection tool, which, in this research, had an online questionnaire to address 23 administrative technicians, and with a frequency distribution table to interpret the results. Empirical evidence has shown that medium/high coherence and minimum complexity favor being and staying in scenes offices, while low coherence and maximum complexity represent the opposite.

KEYWORDS: office scenes, visual preference, ergonomics of the built environment. 


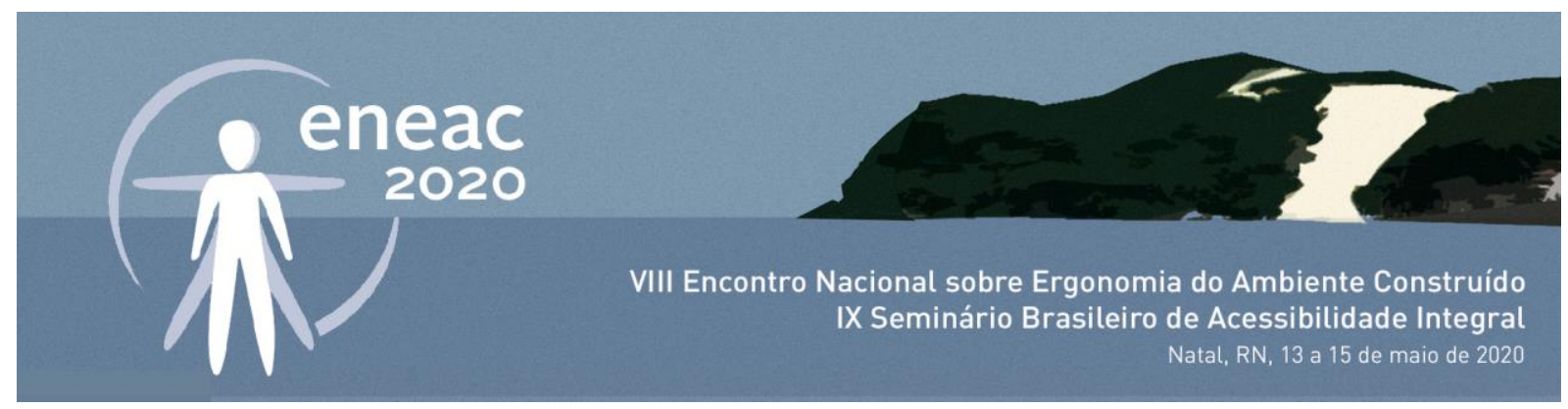

\section{INTRODUÇÃO}

Escritórios são ambientes de trabalho que se destinam à realização de atividades de natureza cognitiva/intelectual e administrativa. De acordo com Oseland (2009), as mudanças ocorridas nas organizações, nas últimas décadas, tanto no contexto da reestruturação das demandas produtivas quanto na experiência de novas relações de trabalho em que os sujeitos estão inseridos, acarretam na aquisição de novos padrões de experiência do trabalhador com o seu ambiente físico laboral.

Desse modo, os ambientes de trabalho têm despertado interesse como objeto de estudo, considerando a importância de projetá-los de forma que atendam não apenas às necessidades das tarefas desenvolvidas, mas sobretudo favoreçam a percepção de conforto e bem-estar dos trabalhadores, promovendo condições ambientais que otimizem sua performance, elevando assim, o padrão de qualidade da empresa (GRAZZIOTTI; TIBIRIÇÁ, 2007). Vasconcelos, Villarouco e Soares (2010) expõem a importância de projetar ambientes ergonomicamente eficazes tanto do ponto de vista funcional quanto formal e estético, para promover um espaço agradável, de prazer e bem-estar.

Diante da necessidade de compreender a inter-relação entre indivíduos no seu contexto de trabalho com os componentes físicos do ambiente, a psicologia vem procurando auxiliar a compreensão da forma como o sujeito percebe e interage com o ambiente, como resultado de suas experiências pregressas além de suas expectativas e intenções de uso (OSELAND, 2009).

Villarouco e Andreto (2008) descrevem como essencial o entendimento da percepção do usuário frente ao ambiente construído, tendo em vista que suas sensações são diretamente afetadas pelas características estéticas. Para Nasar (2000), as características estéticas do ambiente afetam a experiência humana na medida em que provocam sensações que podem favorecer ou restringir o desempenho de uso do espaço. $O$ autor ainda acrescenta que a configuração de tais características pode também influenciar o comportamento humano e o interesse de estar e/ou permanecer no ambiente. Já Okamoto (2002) aponta que, na relação com o ambiente, a mente humana opta por aspectos de interesse ou que chamem a sua atenção, de forma que a percepção dos estímulos produzidos pelo seu espaço físico modula o comportamento do usuário.

Partindo dessas constatações, é importante conhecer o efeito de certas características ambientais na preferência visual, buscando contribuir com informações empíricas aplicáveis a projetos que favoreçam estar e/ou permanecer em ambientes e, por conseguinte, com o bem-estar e o conforto de seus usuários. Por essa razão, duas características de escritórios: coerência e complexidade, foram tomadas para estudo pela relevância que exercem na preferência visual por ambientes.

Considerando a influência das características estéticas, na preferência visual por ambientes, este artigo teve como objetivo prover informações empíricas sobre os efeitos da coerência e da complexidade de cenas de escritórios na preferência visual de seus usuários.

\section{CONSIDERAÇÕES TEÓRICAS}

A natureza do trabalho realizado, assim como as tecnologias e a cultura organizacional vigentes têm interferido no modo de organização dos escritórios.

Os escritórios, atualmente, têm investido em tecnologias que concentram grande parte das atividades administrativas em telas de computador, por opção ou exigências legais, tendo suas 


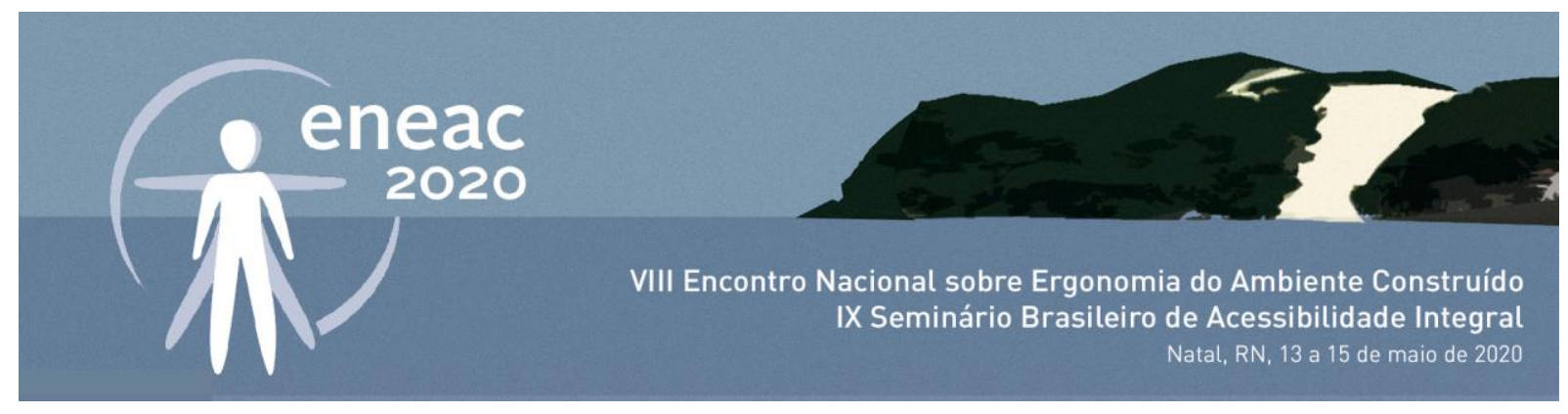

atividades focadas em interfaces computacionais com processos essencialmente digitais. Considerando o incremento dessas demandas cognitivas nas atividades laborais de seus usuários frequentes, é de interesse buscar informações sobre que características ambientais podem influenciar o bem-estar e o desempenho deles, a partir da preferência visual por ambientes.

Nas organizações privadas, as novas formas de trabalho, na atualidade, possibilitaram que, em alguns casos, novos ambientes laborais, como o home-office, escritórios virtuais e coworking, entre outros, surgissem, devido à flexibilidade e baixos custos que apresentam em relação aos escritórios tradicionais. Nas organizações públicas, apesar da adoção de novas tecnologias nas atividades administrativas, inexiste flexibilidade quanto à escolha do ambiente físico de trabalho, exigindo-se, na maioria dos casos, a presença física do trabalhador na empresa.

A ergonomia se preocupa com as relações dos usuários em seus sistemas de trabalho, a fim de realizar projetos para melhorar seu bem-estar e desempenho geral dos sistemas (ABERGO, 2000). Dessa forma, a contribuição da ergonomia em projetos do espaço de trabalho busca a compreensão dos sistemas que compõem a cultura organizacional, já que as interações humano-ambiente, a partir das percepções e sensações que despertam, influenciam o comportamento.

Identificar as atitudes comportamentais e suas influências no ambiente são aspectos que devem ser levados em consideração nos projetos de ambientes, com foco na situação real de trabalho. No caso de ambientes construídos, ajustar a situação de projeto ao humano (COSTA; VILLAROUCO, 2016).

A estética ambiental auxilia a ergonomia do ambiente construído com conceitos e evidências empíricas sobre a relação humano-ambiente (GROSSO, 2018). Entendendo a importância dessa área para a avaliação de lugares, principalmente por não deixar para trás as análises empíricas, esta pesquisa adotou referências de autores como Nasar (1999, 2000, 2008), Kaplan e Kaplan (1989) e Berlyne (1971), visando identificar características notáveis da preferência visual por ambientes.

A relação das características ambientais com o indivíduo ocorre mediante categorias de preferência visual representadas por variáveis formais e outras de conteúdo ou simbólicas (NASAR, 1999). Das variáveis formais que as pesquisas da estética ambiental consideram como relevantes para a imagem avaliativa ou resposta estética, várias emergiram como proeminentes na experiência do ser humano com seu ambiente físico, como, por exemplo, coerência e complexidade, que esta pesquisa elegeu para se concentrar devido à relevância de ambas na experiência ambiental humana. Segundo Kaplan e Kaplan (1989), a coerência refere-se ao grau em que uma cena se encaixa ou faz sentido; enquanto a complexidade se refere à diversidade e riqueza visual da cena.

Segundo Berlyne (1971), autor seminal da estética experimental contemporânea, o interesse aumenta com a incerteza e o estímulo gerados pela complexidade, enquanto a preferência tem uma relação invertida em forma de "U" para o estímulo. A complexidade aumenta com o estímulo até certo ponto (nível moderado de estímulo), e depois diminui para níveis mais altos. Em um estado de baixa estimulação, a incerteza é reduzida pelo aumento da coerência e diminuição da complexidade.

Kaplan e Kaplan (1989) viram falhas nos modelos de avaliação do lugar, baseados no estímulo, e propuseram uma teoria considerando o processamento de informações. De acordo com essa teoria, os humanos preferem lugares que promovam envolvimento e que fazem ou prometem fazer sentido. Mais especificamente, para esses autores, os indivíduos preferem a complexidade por suas qualidades envolventes e a coerência para dar sentido ao ambiente e torná-lo compreensível. 


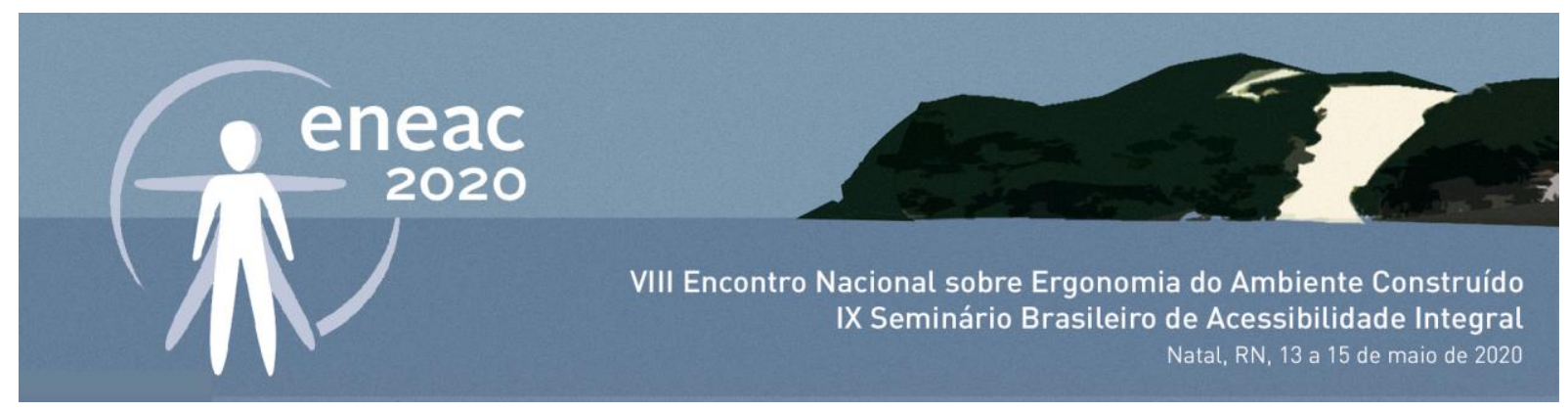

Para Nassar (2008), ambientes com complexidade máxima reduzem a preferência em seus usuários, já ambientes com complexidade moderada tendem a provocar maior preferência humana, quando comparados com outros com mínima e máxima complexidade. Ainda para o autor, em certa medida, a complexidade tem o atributo de estimular o envolvimento, já que a monotonia - presente em ambientes com complexidade mínima - não desperta o interesse dos indivíduos que os utilizam.

No que se refere à coerência (obtida pela redução do contraste), Nasar (2008) apurou a preferência dos usuários por ambientes com coerência alta (contraste baixo). Segundo esse autor, a coerência média (contraste médio) está relacionada com média preferência nas cenas; já cenas de coerência baixa (contraste alto) despertam menor preferência nos usuários em relação a outros níveis. A coerência contribui para reduzir a incerteza e o aumento do tom hedônico (beleza/agradabilidade).

\section{CONSIDERAÇÕES TEÓRICO-METODOLÓGICAS E METODOLÓGICAS}

A presente pesquisa está ancorada em uma abordagem meta-teórica denominada Teoria das Facetas, desenvolvida nos anos 1950, por Louis Guttman. Como um procedimento metodológico, esta abordagem é uma ferramenta útil no delineamento de pesquisas e na coleta, sistematização e análise de dados, facilitando o desenvolvimento de teorias e elaboração de hipóteses (BILSKY, 2003).

A Teoria das Facetas (TF) consiste em uma abordagem teórico-metodológica de grande validade nas investigações empíricas aplicadas à avaliação ambiental, por proporcionar uma clara descrição dos componentes do ambiente e de como são vivenciados pelos usuários (COSTA FILHO, 2014), o que justificou a escolha dessa abordagem para a estruturação da investigação empírica proposta.

A TF estrutura o delineamento da pesquisa em uma sentença semântica que relaciona os elementos teóricos e empíricos identificados com seus possíveis resultados (SOLOMON, 2019). Essa Sentença Estruturadora Geral normalmente reúne três tipos básicos de facetas que representam objetos e/ou variáveis da investigação empírica. Cada faceta é constituída por elementos internos que relacionam de forma exclusiva e abrangente o universo de cada componente da pesquisa (COSTA FILHO, 2014).

O primeiro tipo de faceta define a população da pesquisa e seus eventuais grupos de interesse. 0 segundo tipo diz respeito ao conteúdo das variáveis estudadas. As facetas de conteúdo juntamente com a faceta de população representam o domínio da pesquisa. O terceiro tipo de faceta consiste no universo de reações ou possibilidade de respostas dos sujeitos em relação às variáveis representadas nas facetas de conteúdo (SHYE; ELIZUR; HOFFMAN, 1994). A partir das variáveis selecionadas, definiu-se a Sentença Estruturadora para a avaliação da preferência visual por escritórios (Figura 1).

Figura 1 - Sentença Estruturadora Geral para a avaliação da preferência visual percebida em cenas de escritórios

\begin{tabular}{|c|c|c|}
\hline \multicolumn{3}{|c|}{ Em que medida a pessoa x (técnico administrativo) avalia que as características de } \\
\hline (FACETA X) & & (FACETA Y) \\
\hline CONTRASTE & \multirow{4}{*}{ e } & COMPLEXIDADE \\
\hline (X1) contraste baixo & & (Y1) complexidade mínima \\
\hline (X2) contrate médio & & (Y2) complexidade moderada \\
\hline (X3) contraste alto & & (Y3) complexidade máxima \\
\hline \multicolumn{3}{|l|}{ RACIONAL } \\
\hline \multirow{2}{*}{\multicolumn{3}{|c|}{$\begin{array}{l}\text { (1) nada } \\
\text { (2) pouco }\end{array}$}} \\
\hline & & \\
\hline (3) mais ou menos & \multirow{3}{*}{\multicolumn{2}{|c|}{$\begin{array}{l}\text { estar e/ou permanecer em escritórios } \\
\text { [expressão da preferência visual por esse tipo de espaço] }\end{array}$}} \\
\hline (4) muito & & \\
\hline (5) demais & & \\
\hline
\end{tabular}

Fonte: autores da pesquisa 


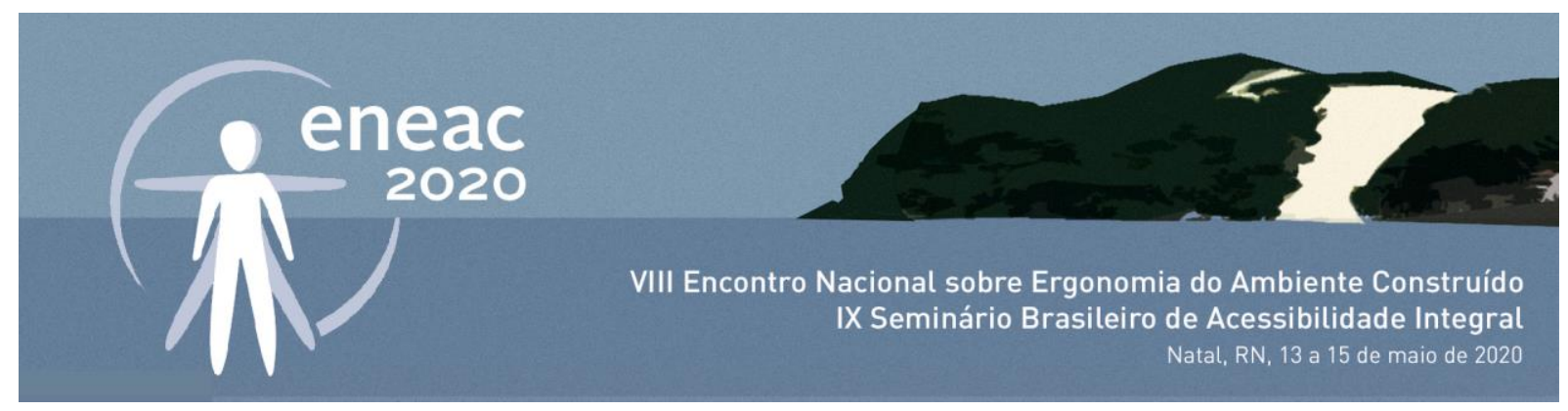

A faceta populacional da Sentença Estruturadora Geral, para a avaliação da preferência visual por escritórios, representa o grupo de usuários abordados na pesquisa, qual seja, técnico administrativo.

As duas facetas de conteúdo estão relacionadas com duas características ambientais presentes em escritórios e, sobretudo, conforme referenciado nas considerações teóricas, devido à relevância de ambas na experiência e preferência ambiental humana. A Faceta $X$, contraste (covariável da coerência), tem como elementos internos três diferentes níveis de intensidade: (X1) contraste baixo; (X2) contraste médio; $(X 3)$ contraste alto. A Faceta $Y$, complexidade, considera também três diferentes níveis: (Y1) mínima; (Y2) moderada; (Y3) máxima.

Os elementos internos dessas facetas de conteúdo podem ser organizados de forma semelhante a uma análise combinatória, produzindo nove diferentes conjuntos $(X 3 \times Y 3=9)$, que transmitem uma relação ou situação específica a ser avaliada.

Cada uma dessas situações específicas compartilha de um racional, sistematizado em uma escala "Likert" de cinco pontos: (1) nada; (2) pouco; (3) mais ou menos; (4) muito; (5) demais, para a medida em que as características de contraste (coerência) e de complexidade favorecerem estar e/ou permanecer em escritórios.

No que se refere às considerações metodológicas, inicialmente, cabe destacar que a pesquisa de campo realizada consistiu em uma investigação empírica quantitativo-descritiva, que objetivou, como função primordial, a descrição de certas características quantitativas de populações como um todo, utilizando escalas que permitem a quantificação (MARCONI; LAKATOS, 2003).

A elaboração do instrumento de coleta de dados teve como diretriz o universo de situações possíveis do mapeamento dos três elementos internos das duas facetas de conteúdo $(X$ e $Y)$, relacionadas na Sentença Estruturadora Geral, para a avaliação da preferência visual por cenas de escritórios (Figura 1), tendo resultado em nove questões, cada uma delas vinculadas a uma cena de ambiente de escritório, com diferentes níveis de contraste e complexidade (Quadro 1 - Página Seguinte)

Cada cena utilizada como elemento de estímulo nas avaliações foi selecionada previamente, no banco de imagem de escritórios do Google, e submetidas a um corpo de juízes composto por 11 alunos do Curso de Mestrado Profissional em Ergonomia, da Universidade Federal de Pernambuco, buscando o consenso visual percebido sobre os níveis de contraste e complexidade indicados.

Os dados foram coletados por meio de um questionário on-line, disponibilizado pelo "GoogleForm", em que foi solicitado aos participantes, convidados por e-mail pelos autores da pesquisa, para indicarem em que medida as nove cenas favoreciam estar e/ou permanecer em escritórios, e o próprio sistema realizava o ordenamento dos dados.

Findo o prazo estipulado para a coleta, o número de vezes que cada cena foi selecionada pelos respondentes foi registrado em uma tabela de distribuição de frequências, para condensar a classificação nos três diferentes níveis ofertados para respostas, permitindo melhor compreensão dos efeitos do contraste (coerência) e da complexidade sobre a preferência visual por escritórios.

A população amostral, escolhida por tipicidade, foi composta por técnicos administrativos de duas IES públicas, Universidade Federal de Pernambuco (UFPE) e Universidade Federal de Alagoas (UFAL), sem fazer uso de formas aleatórias de seleção, caracterizando a amostragem como não probabilística, portanto sem possibilidade de generalização dos resultados, representando apenas um indicativo da situação-problema que se buscou investigar. 

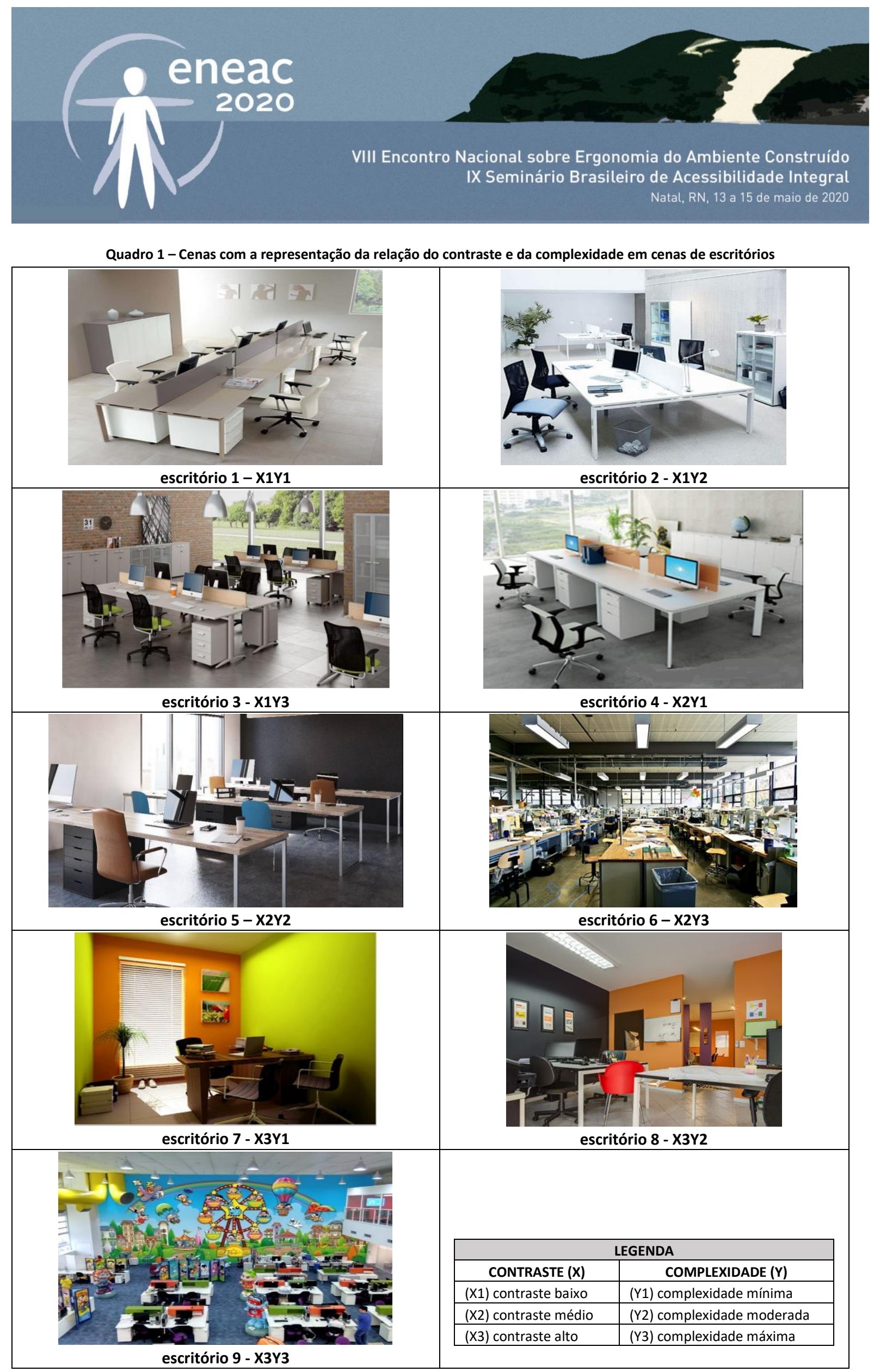

Fonte: Banco de imagens de escritórios do Google 


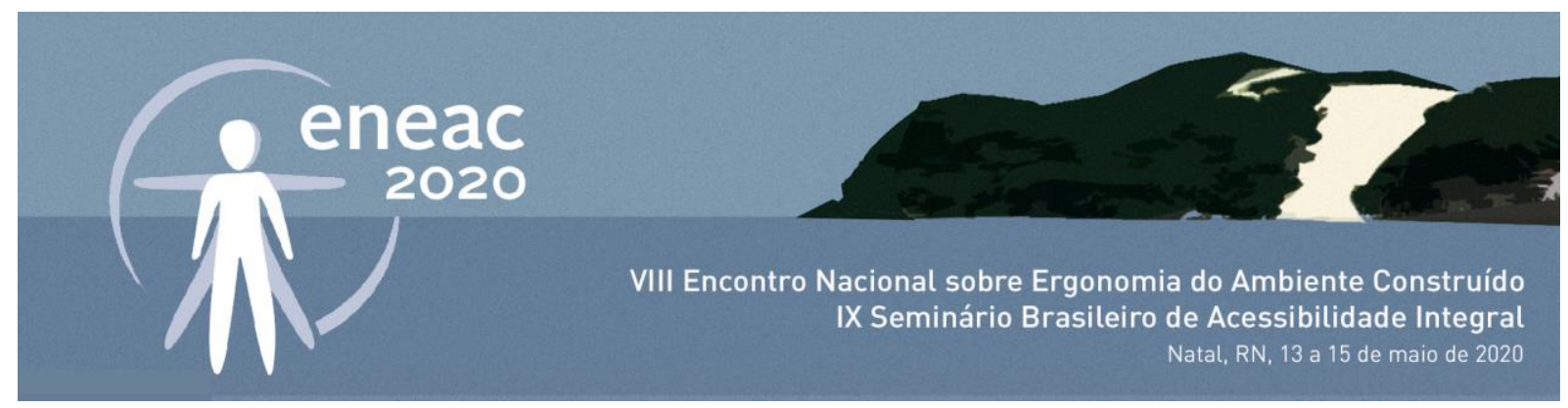

\section{CONSIDERAÇÕES EMPÍRICAS}

A população amostral desta pesquisa foi composta por 23 participantes, técnicos-administrativos das duas Instituições de Ensino Superior públicas, anteriormente descritas, de ambos os gêneros, sendo 06 do masculino e 17 do feminino, com idades variando de 25 a 59 anos. Todos possuíam grau de escolaridade superior, ocupando cargos de níveis médio e superior nas universidades.

Na Tabela 1, foi condensada a distribuição das frequências, relacionadas com a preferência visual para as nove cenas de escritórios - utilizadas como elemento de estímulos no questionário online - e a escala de cinco pontos disponibilizada para as respostas, relacionada com a medida em que cada uma das cenas apresentadas favorecia estar e/ou permanecer em escritórios.

\begin{tabular}{l|c|c|c|c|c|c|c|c|c}
\multicolumn{1}{c}{ Tabela 1 - A preferência visual percebida nas nove cenas de escritórios } \\
\hline Nada & $\mathbf{X 1 Y 1}$ & $\mathbf{X 1 Y 2}$ & $\mathbf{X 1 Y 3}$ & $\mathbf{X 2 Y 1}$ & $\mathbf{X 2 Y 2}$ & $\mathbf{X 2 Y 3}$ & $\mathbf{X 3 Y 1}$ & $\mathbf{X 3 Y 2}$ & $\mathbf{X 3 Y 3}$ \\
\hline Pouco & 1 & 1 & 6 & 0 & 0 & 15 & 5 & 1 & 12 \\
\hline Mais ou Menos & 1 & 3 & 11 & 1 & 4 & 7 & 6 & 5 & 6 \\
\hline Muito & 9 & 6 & 1 & 3 & 9 & 1 & 4 & 11 & 5 \\
\hline Demais & 11 & 12 & 4 & 15 & 9 & 0 & 5 & 6 & 0 \\
\hline TOTAL & 1 & 1 & 1 & 4 & 1 & 0 & 3 & 0 & 0 \\
\hline & 23 & 23 & 23 & 23 & 23 & 23 & 23 & 23 & 23 \\
\hline
\end{tabular}

Ao explorar a distribuição das frequências dos dados na Tabela 1, pôde-se interpretar os efeitos integrados do contraste (coerência) e da complexidade em cenas de escritório, sobre a preferência visual percebida pela população amostral, evidenciando as relações entre os elementos internos das duas facetas, estabelecidas na Sentença Estruturadora Geral para a avaliação proposta.

Os dados, inicialmente de modo amplo, revelam o efeito sugerido da coerência (obtida pela redução do contraste) e omitem o efeito presumível da complexidade na preferência visual dos participantes estarem e/ou permanecerem em escritórios.

Quanto ao contraste, mais especificamente, a preferência visual dos participantes é elevada para as cenas de escritórios com contraste baixo (coerência alta) e contraste médio (coerência média), ambos os níveis com escores quase semelhantes, sendo muitíssimo menor para o nível de contraste alto (coerência baixa). $O$ resultado, como dito antes, corrobora com o sugerido nas considerações teóricas, ou seja, o ambiente precisa ser coerente para ser compreendido.

Em relação à complexidade, também de modo específico, a preferência visual dos respondentes é elevada para cenas de escritório com complexidade mínima, reduz para cenas com complexidade moderada, sendo menor para cenas com complexidade máxima. Esses achados, também como dito antes, diferem do que é sugerido nas considerações teóricas.

Nasar (2008) alerta que os achados empíricos para a complexidade têm sido inconsistentes, talvez por causa do aparato metodológico, como, por exemplo, falha no controle de covariáveis naturais da complexidade, níveis de complexidade suficiente para que ocorra a retração do prazer, enquanto outros ainda ignoraram a possibilidade de relacionamentos não lineares. 


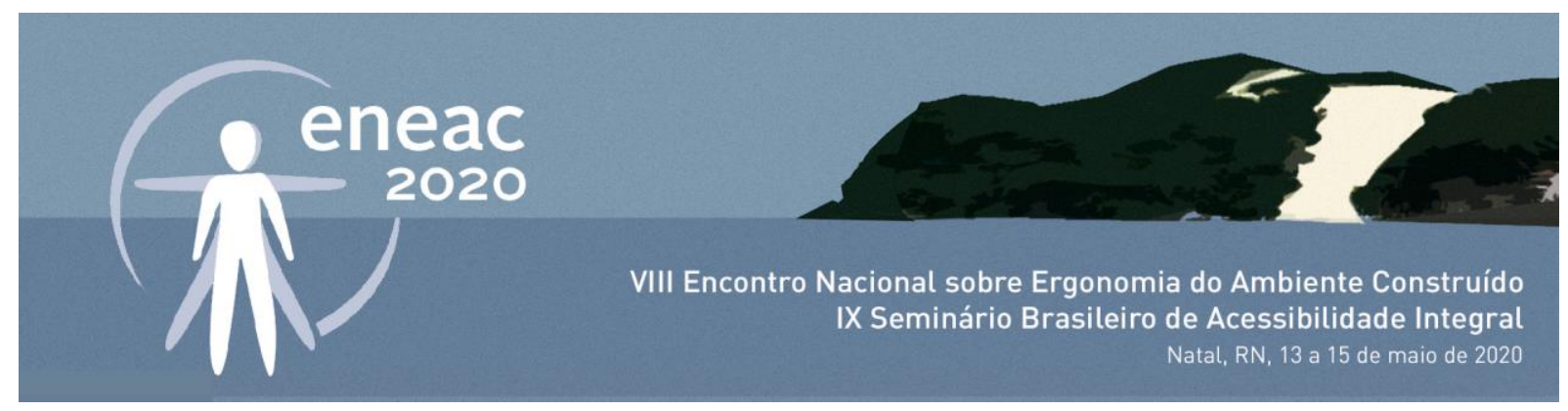

A cena de escritório visualmente preferida pelos participantes apresenta contraste médio (coerência média) e complexidade mínima, como pode ser observado, por exemplo, na imagem X2Y1 (Quadro 1), enquanto a cena $X 2 Y 3$, com contraste médio (coerência média) e complexidade máxima, representa o oposto. A partir desse achado, em que ambas as cenas de escritório têm o mesmo nível de contraste, é possível sugerir que foi a complexidade da cena que norteou as escolhas relacionadas com a preferência visual por cenas de escritório.

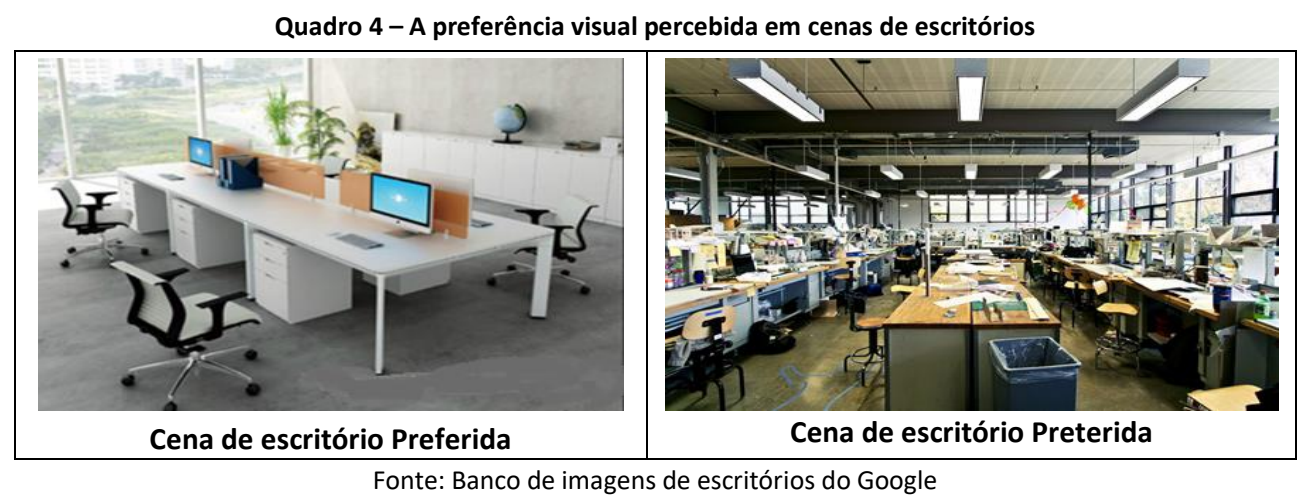

A partir das evidências empíricas, para que as características de contraste e de complexidade de escritório favoreçam a preferência visual dos seus utilizadores, o contraste baixo ou médio (coerência alta ou média) e a complexidade mínima devem ser encorajados nos projetos para esse tipo de espaço. Deixa-se, então, as recomendações de explorar diferentes cores, texturas, formas e materiais nos ambientes de escritório, mas racionalizar bastante o número e a diversidade de elementos na cena para garantir mínima complexidade visual.

\section{CONCLUSÃO}

Baseados nos resultados para as cenas utilizadas na investigação empírica desta pesquisa, conclui-se que o contraste de médio a baixo (coerência de média a alta) e a complexidade mínima, corroborando parcialmente com as sugestões teóricas, elevam a preferência visual em escritórios.

Foi também possível verificar que a complexidade mínima das cenas norteou a preferência visual de estar e/ou permanecer em escritórios, segundo os técnicos administrativos consultados, ou seja, quanto maior a complexidade da cena, menor a preferência visual por esse tipo de espaço.

Sempre é valido reiterar que esses achados empíricos não devem ser tomados de uma maneira simplista, pois refletem as preferências visuais para o tipo de elemento de estímulo apresentado aos participantes abordados como suporte no questionário online, a população amostral selecionada, e o local e a época em que a investigação foi realizada.

No mais, cabe destacar que este tipo de abordagem sobre a avaliação de lugares - considerações teóricas, teórico-metodológicas e metodológicas - iniciou-se em Costa Filho (2012), e continua sendo desenvolvida em diversas pesquisas em parcerias, realizadas pelo autor no Núcleo de Design e Comunicação, no Programa de Pós-Graduação em Design e no Programa de Pós-Graduação em Ergonomia, todos da mesma Instituição: Universidade Federal de Pernambuco. 


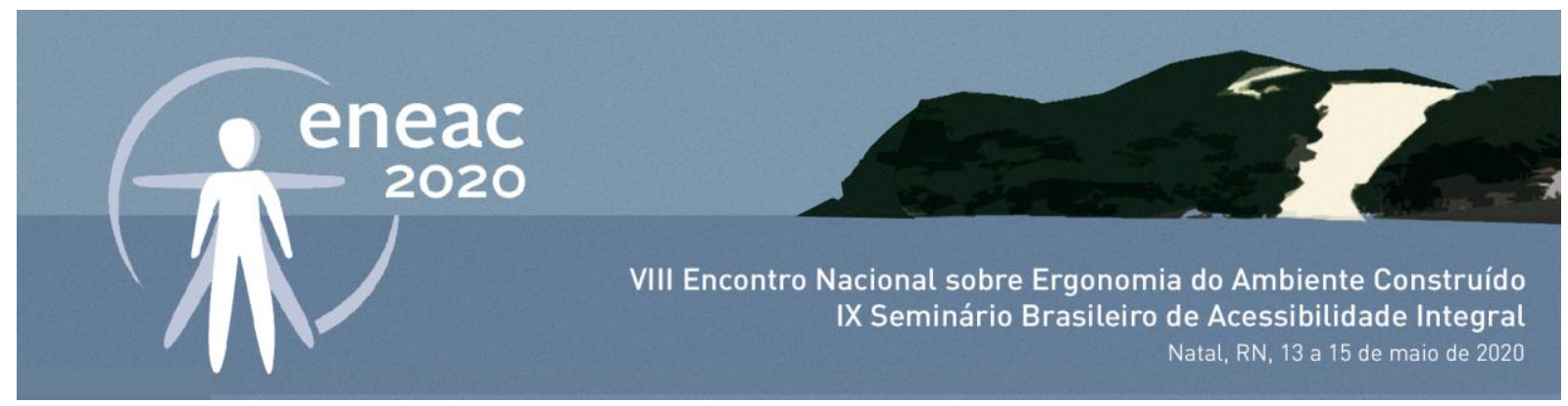

\section{REFERÊNCIAS}

ABERGO, Associação Brasileira de Ergonomia. O que é ergonomia. Disponível em:

<http://www.abergo.org.br/internas.php?pg=o_que_e_ergonomia>. 2000. Acesso em 17 de out. 2019.

BERLYNE, D. E. Ends and meanings of experimental aesthetics. Canadian Journal of Psychology, 26, 1972. p 303-325.

BILSKY, W. A Teoria das Facetas: noções básicas. Estudos de Psicologia, v. 8, n. 3, p. 357-365, 2003.

COSTA, A. P. L., VILLAROUCO, V. Intervenção Ergonômica em Posto de Atendimento ao Público: um estudo de inserção da ergonomia em projetos arquitetônicos. VI ENCONTRO NACIONAL DE ERGONOMIA DO AMBIENTE CONSTRUÍDO E VII SEMINÁRIO BRASILEIRO DE ACESSIBILIDADE INTEGRAL, 2016. Recife. Anais... Recife, UFPE. 2016.

COSTA FILHO, L. L. O enfoque da teoria das facetas na avaliação de lugares. In: V ENEAC - ENCONTRO NACIONAL DE ERGONOMIA DO AMBIENTE CONSTRUÍDO E VI SEMINÁRIO NACIONAL DE ACESSIBILIDADE INTEGRAL, 2014. Rio de Janeiro. Anais... Rio de Janeiro, PUC-Rio, LEUI/PUC - Rio. 2014.

MIDIÁPOLIS: comunicação, persuasão e sedução da paisagem urbana midiática. 2012. 271f. Tese (Doutorado). Programa de Pós-graduação em Desenvolvimento Urbano Universidade Federal de Pernambuco, Recife, 2012.

GRAZZIOTTI, A.G; TIBIRIÇÁ, A.C.G. A Ergonomia no ambiente de escritórios. In: III WORKSHOP DE ANÁLISE ERGONÔMICA DO TRABALHO NA UFV, 2018, Viçosa. Anais... Viçosa: 2018, p. 1-18.

GROSSO, A. C. M. Qualidade visual percebida em cenas do edifício do Centro de Artes e Comunicação da Universidade Federal de Pernambuco. Dissertação (Mestrado Profissional em Ergonomia) - Centro de Artes e Comunicação, Universidade Federal de Pernambuco. Recife, p. 175. 2018.

KAPLAN, S., KAPLAN, R. The experience of nature: A psychological perspective. New York: Cambridge University Press, 1989 MARCONI, M. A., LAKATOS, E. M. Técnicas de pesquisa: planejamento e execução de pesquisas, amostragens e técnicas de pesquisas, elaboração, análise e interpretação de dados. 5. ed. São Paulo: Atlas, 2002.

NASAR, J. L. Visual quality by design. Michigan: Haworth, Inc., 2008.

The evaluative image of places. In WALSH, W. B.; CRAIK, K. H.; PRINCE, R. H. 2nd. ed. (Eds.). Person-environment psychology: new directions and perspectives. New Jersey: Lawrence Erlbaum Associates, 2000. p. 117-168.

Urban design aesthetics: The evaluative qualities of building exteriors. In: Environment and Behavior, Vol. 26, № 3, May 1994. 377-401, 1994

OKAMOTO, J. Percepção ambiental e comportamento. São Paulo: Mackenzie, 2002.

OLIVEIRA, C. K.; COSTA FILHO, L. O efeito da complexidade e da coerência de escritórios de coworking na qualidade visual percebida. In: VII ENCONTRO NACIONAL DE ERGONOMIA DO AMBIENTE CONSTRUÍDO E VIII SEMINÁRIO BRASILEIRO DE ACESSIBILIDADE INTEGRAL, 2018, Fortaleza. Anais... São Paulo: Editora Blucher, 2018. v. 4. p. 1-12.

OSELAND, N. The impact of psychological needs on office design. Journal of Corporate Real Estate, v. 11, n. 4, p.244-254, 2009.

SHYE, S.; ELIZUR, D.; HOFFMAN, M. Introduction to Facet Theory: content design and intrinsic data analysis in behavioral research. London: Sage Publications, 1994.

SOLOMON, E. Guest Editors' Introduction Facet Theory in Organizational Research. International Studies of Management \& Organization, v. 49, n. 3, p. 233-246, 2019.

VASCONCELOS, C. F.; VILLAROUCO, V.; SOARES, M. M. Contribuição da Psicologia Ambiental na análise ergonômica do ambiente construído. Ação Ergonômica, v. 5, n. 3, p. 14-20, 2010

VILLAROUCO, V.; ANDRETO, L. F. M. Avaliando desempenho de espaços de trabalho sob o enfoque da ergonomia do ambiente construído. Produção, v. 18, n. 3, p. 523-539, 2008. 